\title{
Multi-organ Transplantation Center in Romania: a story of persuasion for a controverted issue
}

\author{
Narcis COPCĂ \\ "St.Maria" Clinical Hospital; Bucharest Academy of Economic Studies, Romania \\ narciscopca@gmail.com
}

PICBE | 421

Constanța MIHĂESCU-PINȚIA

National School of Public Health, Management and Professional Development; "St.Maria"

Clinical Hospital, Bucharest, Romania

cipivil@yahoo.com

\begin{abstract}
Many countries built their own models of transplantation, collaborating to exchange knowledge and donor organs for effectively help their patients in need. Despite great clinical research on transplantation, literature regarding its management is scarce. Transplantation is quite a controverted issue in Romania, without a culture of donation, within a poor healthcare system. Yet, first attempts were in early $20^{\text {th }}$ century, and modern transplantation started since 1995. There was always a shortage of organs, but after recent press scandals, people became more reluctant to donate, therefore transplantations went down, dramatically impacting patients. Our objective is to emphasize opportunity, need and sustainability for developing a multi-organ transplantation center in Romania, of regional importance, in order to better serve our patient needs in an effective and efficient manner. This research used descriptive analysis, secondary data compilation and review, legislative diagram, case study. Currently there are 68 transplantation centers accredited in Romania with 13,702 transplants accomplished (organs, tissues, cells), at a rate of 19.3/million, covering 19.4 millions of people living just 75.5 years in average (EU=80.2). But 5,400 Romanian patients wait for a transplant, while 550 died waiting... After modernization and building a great surgical center and team, Clinical Hospital St. Maria of 300 beds started complex surgery and successful liver transplantation in 2014, continued with lung transplant in 2018 - Romanian premiere, after many struggles. Next step is a modern multi-organ transplantation center. Vision, persuasion and effective leadership are crucial. Romanian potential for overspecialized surgery is greater than actual practice. Experience indicates that multi-organ transplantation centers are more effective and efficient than separated ones, by concentrating the best specialists, technology, knowledge and resources available for harvest, transplant and care, thus improving health outcomes (donors, successful transplants, lives saved, quality of life), prestige, retention of excellent professionals, and trust in healthcare system, at lower costs than in developed countries.
\end{abstract}

Keywords: Transplantation, Life-saving, Multi-organ Transplantation Center, Healthcare Leadership, Healthcare Performance.

\section{Introduction}

Even the idea of replacing damaged body parts seems to originate in ancient times, transplantation became a successful medical procedure during the second half of the $20^{\text {th }}$ century, after many attempts (Barker \& Markmann, 2013), refined for saving lives and improving the quality of life.

Transplantation is currently a great medical performance accomplished by a highly complex surgical procedure accompanied by specific medical testing and intensive care 
services, recommended to an increasing number of critical patients, reliant on donation. Many countries across the world, mainly the highly developed ones, have built their own models and systems of organ-tissue-cell transplantation, according to their health needs, resources, experience and values. Regional collaboration for exchanging crucial knowledge and donor organs to effectively help those patients in need, appears to be a valuable mutual advantage.

Despite the fact that transplantation is the only chance those patients have to stay alive, and excellent specialists are available, this highly performance service is not enough acknowledged, nor developed, in Romania. Still approached as a controverted issue and too expensive procedure, without a culture of donation and within a poor healthcare system so much criticized, human transplantation is currently far off the population needs, EU standards and its actual potential.

While first attempts to achieve human transplant appeared here in early $20^{\text {th }}$ century, yet modern transplantation started to develop late in 1995 within the best medical university centers, but without a strategic perspective. There was always a shortage of organs, but after press scandals, people became even more reluctant to donate, therefore the transplantations dropped dramatically, thus impacting the patients from waiting lists (e.g. from 138 deceased donors and 448 solid organ transplants or 20.74/mil. inhabitants achieved in 2014, compared to European average of 44.23/mil., to just 65 deceased donors and 215 transplants or 10.91/mil. in 2017, as opposed to European average of 61.64/mil.) (NTA, GODT, 2018).

Our objective is to emphasize the opportunity, need, sustainability and effectiveness for developing a modern multi-organ transplantation center in Romania, of regional importance in South-Eastern Europe, within the Santa Maria Clinical Hospital in Bucharest. This endeavor is an authentic managerial challenge within the worst quoted healthcare system among European Region, as Romania ranked 34 after scoring 439 points in the European Health Consumer Index 2017 (Bjornberg, 2018).

\section{Literature review}

\section{Managing transplantation}

Despite the continuing robust clinical research and dissemination on transplantation, there is a lack of literature regarding the organization, financing, governance, leadership and networking of the transplantation centers in the countries and regions. Hospital leadership and management represent another field quite poorly covered by specific academic research. One of the reasons resides in the huge differences existing between the national healthcare systems, even belonging to the same model, and also significant differences between the hospitals themselves including those within the same country and category.

However, there are certain conclusions of studies we consider very relevant to our paper in terms of hospital and transplantation leadership. An interesting expert opinion alerted that the usual leadership model of public hospitals, usually characterized by traditionalism, inflexibility, control, autocracy, is no longer a right response to multiple, complex challenges of hospital governance (Saltman et al, 2011) in a globalized world.

On the other hand, the evidence gathered by a literature review has indicated that transformational and authentic leadership - supportive, available, committed, honest, learning, motivational, empowering, visionary - are clearly related to great performance and high quality in healthcare (West et al, 2015). The three axioms - situational, non-hierarchical, 
relational - are considered fundamental for health leadership by Hodgetts, while the effective leadership is seen as the common denominator of all the criteria used to assess successful hospital management in UK Top Hospital Award: quality and change, safety, leadership, organizational culture, and external influence. This author also observed that hospital leadership is not just a one-way process, of the leader driving the organization, but also viceversa, the structure and culture of organization could be able to modify and even destroy the leader on long run (Hodgetts, 2011).

Literature and practice indicate us an increasing need to approach and manage the public hospital, especially the clinical one, in a more flexible, adaptable, modern, innovative and responsible manner, thus able to effectively respond to the patient needs and expectations, within a more challenging environment.

Transplantation may be defined as a very complex surgical procedure for replacing a severely deteriorated, dysfunctional part of the human body (organ, tissue, cells) with a compatible healthy, functional part. The transplanted part may derive from: the same organism; a living donor, different than the beneficiary (a relative, or not); a brain-death donor; sometimes an animal, other times even an artificial replacement. Clinical definition is more technical, indicating transplantations as "the transfer (engraftment) of human cells, tissues or organs from a donor to a recipient with the aim of restoring function(s) in the body; when transplantation is performed between different species, e.g. animal to human, it is named Xenotransplantation". (GODT, WHO, 2009) The European Directive 2010/45/EU on standards of quality and safety of human organs intended for transplantation, introduces in definition the concept of process "intended to restore certain functions of the human body by transferring an organ from a donor to a recipient". Kidney and liver are the most frequent organ transplantations performed world-wide.

The two-stage intervention (of removing the damaged part, and replacing it with the new harvested organ/tissue) is clinically complicated, risky and expensive, but vital for an increasingly number of patients. And only highly trained and experienced doctors are able to successfully perform it within a complex team. According to the Organ Procurement and Transplantation Network of the U.S. Human Department of Health and Human Services, this special team should be formed by: 1) clinical transplant coordinators - in charge with patient treatment, care, evolution and follow-up, 2) transplant physicians - managing the case in terms of medical tests, care, medication, with or without follow-up care, 3) transplant specialized surgeons - who actually perform the surgical procedure and follow-up care of patient, 4) financial coordinator (link between the hospital, insurer, health authorities in terms of costing and billing the transplanted cases), and 5) social workers - supporting both the patient and their family to cope with the state as transplanted with so many challenges. (OPTN, 2018).

On the other hand, the transplantation center is defined by the European Directive 2010/45/EU, applicable in Romania, as "a healthcare establishment, a team or a unit of a hospital or any other body which undertakes the transplantation of organs and is authorised to do so by the competent authority under the regulatory framework in the Member State concerned".

From the ethical point of view, human transplantation has represented a vivid source of controversy and critiques, even nowadays. The main issues in question refer to several dilemmas: how to issue a fair, equitable access to transplantation to everyone in need; if 
people should be encouraged to donate their organs and the proper way of expressing this option; if a prioritization on waiting lists for transplantation should be done on certain criteria; if financial reward of living donors is acceptable or just a perverse inventive; if survival odds are to be primary taken into consideration for transplant.

As transplantation is an exceptional medical performance, we consider that another vital ingredient for its success, especially in developing countries, is the exceptional leadership, defined by Dye and Garman through a series of critical competencies, such as: being visionary, communicating and sharing your vision; building, developing, mentoring, motivating, energizing medical/surgical teams; building consensus within organization and also within transplantation network; proving emotional intelligence, generating informal power, earning loyalty and trust; giving feedback, cultivating adaptability, stimulating creativity and driving results (Dye \& Garman, 2006); in result, inspiring others.

\section{Managing transplantation in Romania}

Romanian path of this extraordinary medical achievement is interesting, teaching us also a leadership lesson. First attempts happened during the first half of $20^{\text {th }}$ century in Bucharest, with experimental unsuccessful kidney transplants of doctor Florescu. In 1958, first skin graft is performed by professor Agrippa Ionescu, while in 1962 the first cornea transplant is registered; experimental liver transplants are done within the main medical university centers, with the first success with alive donor is achieved by professor Eugeniu Proca in 1980; since communism fall, only a few kidney transplants are achieved. Year 1995 marked the start for development of modern transplantology in Romania, with several steps: an IEC campaign, organizing and financing the National Public Transplant Health Program, and a network of centers - including the Clinical Institute "Fundeni" Bucharest, Clinic Institute of Urology and Kidney Transplant Cluj-Napoca, Clinical Emergency Hospital Bucharest (wellknown as "Floreasca"), and Targu-Mures Clinical District Hospital.

The year 1997 pointed out the setting of the National Transplantation Agency, as the state authority in charge with transplant coordination in our country, and foundation of Romtransplant - the professional society of Romanian transplantologists gathering our specialists with their medical and scientific achievements. Since 1998, Romania issued the Law regarding human tissue and organ harvest and transplantation, updated and included within the Law no. 95/2006 for the health system reform. And the specific training of the transplant coordinators has started since the end of ' 90 s.

Within the Romtransplant congress held in 2000, the Patriarch announced the official agreement and support of the Romanian Orthodox Church for organ donation and organ harvesting from persons diagnosed with brain death in our country, which was an important signal for the people as the great majority (87\%) are orthodox.

The standards for cell/tissue donor selection and evaluation, as well as technical requests for cell/tissue donation, takeoff, testing, preservation and processing, were approved in 2007 and periodically updated.

The National Transplantation Registry (NTR) has been set up in 2009 through the Minister of Health Order no.477/2009, issuing the persons in charge with NTR administration in the healthcare facilities accredited for performing transplantation of human organs, tissues and cells for therapeutic purpose, and the registration data for issuing the unique registration code in the National Transplantation Agency. Currently, the 
Romanian NTR comprises the following 10 specific National Registers for: cardiac transplant, hepatic transplant, kidney transplant, lung transplant, pancreas transplant, skin graft, bone and tissue, cornea, in vitro fertilization, and stem hematopoietic cells. (ANT, 2018) And the National Registry of Organ, Tissue and Cell Donors have been set up in 2012, according to the Order 1158/2012 signed by the Minister of Health and the Minister of Justice.

Following the European model, since 2005 we started to celebrate the National Transplantation Day, an excellent opportunity to gather representantives of all the stakeholders in order to discuss medical updates, news, achievements, problems encountered and possible options: saving physicians, public authorities, transplanted patients, patient associations etc.

Specific accreditation criteria for human transplantation of organs, tissues and cells have been developed and issued in Romania for organ harvesting centers, organ transplantation centers, HLA laboratories for transplant activity, organ labeling and packing for transport, tissue transplant centers, central and peripheral blood hematopoietic stem cells transplant centers, according to the Minister of Health Order 860/2013, with following updates.

Our legislative framework is concordant with the European Directives and strategic documents regarding the human transplantation as following: Directive 2010/53/EU Quality and safety of organs intended for transplantation; Directive 2012/25/EU Information procedures for the exchange, between Member States, of human organs intended for transplantation; Action Plan on Organ Donation and Transplantation: Strengthened Cooperation between Member States (EU, EUR-Lex).

But performance in transplantation depends on two distinct components: medical transplantation centers (team of specialists trained and experienced, sophisticated equipment / technology, adequate dedicated spaces, organization of activity, specific drugs and materials, appropriate financing and management), and donation of solid organs, tissues and cells, which is a very sensitive activity hanging upon people education and believes.

A recent study on public hospital governance in Romania indicated several recommendations with relevance for transplantation centers: implement a consensus-based policy making including for hospital reconfiguration and governance, which will allow better planning, standards, classification and incentives for performance; update and improve hospital reimbursement; reform hospital purchasing system; "reconsider the business models" based on population specific healthcare needs and financial limitations; invest in hospital managerial competences. (Duran et al, 2018)

\section{Methodology}

Our goal and hypothesis for this paper is to highlight the medical, managerial and business opportunity to develop a multi-organ transplantation center within the Santa Maria Clinical Hospital in Bucharest, in premiere for Romania and the region of South-Eastern Europe.

In order to design and elaborate this research paper, we decided to use the following methods, techniques and tools: literature review on the subject of management and leadership for transplantation centers; descriptive analysis of the current situation in Romania; compilation, review and comparison of secondary data about transplantations in Romania and other countries and regions; legislation diagram relevant to our subject; presentation and analysis of the St. Maria Clinical Hospital as the recipient proposed to host 
the future center for multi-organ transplantation (structure, activity, performance indicators, advantages, initiatives, steps forward, possible barriers).

Given the sensitivity and novelty of the subject proposed in this paper, a statistical analysis of secondary data available on global transplantations is not considered relevant, while the analysis of clinical data related to transplantations achieved in St. Maria Clinical Hospital does not serve our purpose, being the subject of specialized medical conferences.

PICBE $\mid 426$

Limitations of our study: scarcity of literature - research and evidences - regarding the management and effectiveness of transplantation centers, including multi-organ transplantation centers; uncertainty of organ donation in Romania, especially in the light of recent scandals conducting to a dramatic decrease, which makes transplantation estimates very hard to plan (number, indicators); for ethical reasons, the subject of human transplantation is difficult to be associated with a business approach, despite the need for efficiency given the huge costs involved.

\section{Results and discussions}

There are currently in total 68 accredited transplantation centers across Romania, the great majority being located in Bucharest and the rest of them in other big university centers - Iasi, Cluj-Napoca, Timisoara and Targu-Mures, and just a few remaining are in other cities.

In order to have an up-to-date view of the Romanian transplantology, in the table below is presented the distribution of centers, transplants achieved, patients waiting and patients deceased on each type of transplant. All the persons who died waiting for a transplant and the patients currently waiting on the list form the demand expressed for these services, while the need even exceeds this demand.

Table 1. Current capacity for human transplantation in Romania: centers and activity

\begin{tabular}{|l|l|l|l|l|}
\hline Transplantation & $\begin{array}{l}\text { Number of } \\
\text { centers }\end{array}$ & $\begin{array}{l}\text { Number of } \\
\text { transplants } \\
\text { achieved }\end{array}$ & $\begin{array}{l}\text { Waiting } \\
\text { list }\end{array}$ & $\begin{array}{l}\text { Patients } \\
\text { deceased }\end{array}$ \\
\hline Heart, heart-lung & 4 & 87 & 33 & 70 \\
\hline Reproductive cells & 23 & 9,764 & 1291 & 0 \\
\hline Stem hematopoietic cells & 5 & 944 & 407 & 87 \\
\hline Cornea & 6 & 345 & 238 & 0 \\
\hline Liver & 4 & 613 & 576 & 271 \\
\hline Bone and tissue & 17 & 86 & 22 & 0 \\
\hline Lung & 1 & 4 & 3 & 1 \\
\hline Kidney & 5 & 1,862 & 2835 & 130 \\
\hline Pancreas & 3 & 21 & $\ldots$ & $\ldots$ \\
\hline Total & $\mathbf{6 8}$ & $\mathbf{1 3 , 7 2 6}$ & $\mathbf{5 4 0 5}$ & $\mathbf{5 5 9}$ \\
\hline
\end{tabular}

A comparative image of transplantations, as absolute numbers and rates per million of inhabitants, is presented in the table and the figure below, for the purpose of ranking Romania among other countries in the region. Although the latest transplantation data available internationally are since 2017, we chose to analyze 2016 data because Romania registered a dramatic decrease in donation and implicitly in transplantation during 2017. 
Table 2. Comparative view on transplantations achieved in selected countries / regions, 2016

\begin{tabular}{|l|l|l|l|l|l|l|l|l|l|l|}
\hline $\begin{array}{l}\text { Country } \\
\text { TR }\end{array}$ & USA & Canada & Germany & France & Spain & Poland & Hungary & Romania & Europe & World \\
\hline donors & 9970 & 758 & 857 & 1859 & 2019 & 542 & 182 & 124 & 12514 & 34204 \\
\hline Kidney & 19858 & 1732 & 2094 & 3615 & 2997 & 1108 & 342 & 265 & 26726 & 78519 \\
\hline liver & 7841 & 580 & 888 & 1322 & 1159 & 345 & 81 & 97 & 9990 & 27218 \\
\hline heart & 3209 & 204 & 297 & 490 & 281 & 101 & 58 & 11 & 2686 & 7457 \\
\hline lung & 2345 & 302 & 328 & 384 & 307 & 35 & 17 & 0 & 2090 & 5432 \\
\hline pancreas & 1013 & 95 & 97 & 90 & 73 & 38 & 6 & 1 & 838 & 2284 \\
\hline $\begin{array}{l}\text { small } \\
\text { bowel }\end{array}$ & 147 & 5 & 4 & 3 & 4 & 0 & 0 & 0 & 40 & 219 \\
\hline Total TR & 34413 & 2918 & 3708 & 5904 & 4821 & 1627 & 504 & 374 & 42370 & 121129 \\
\hline
\end{tabular}

Source: Global Observatory on Donation and Transplantation (GODT), January $4^{\text {th }}, 2019$

* TR = transplant

But the relevance of these achievements is conferred by the rates of absolute numbers per million inhabitants and by comparison between cases transplanted and the waiting lists of those remaining to benefit of this treatment. In terms of rates, Spain and the United States are on the top of countries in the world known for the donation of organs and for transplants accomplished. Unfortunately, Romania scores low on both indicators, with just 6.38 donors/mil. and $19.28 \mathrm{TR} / \mathrm{mil}$. in 2016, in comparison with both developed and developing states, including many former socialist countries in the region (Hungary 18.57 donors/mil. and 51.43 TR/mil.; Poland 14.04 and 42.14; Czech Republic 25.33 and 76.29; Slovakia 13.33 and 37.04), while the European averages are 15.72 deceased donors / mil and $53.22 \mathrm{TR} / \mathrm{mil}$. (GODT, 2018)

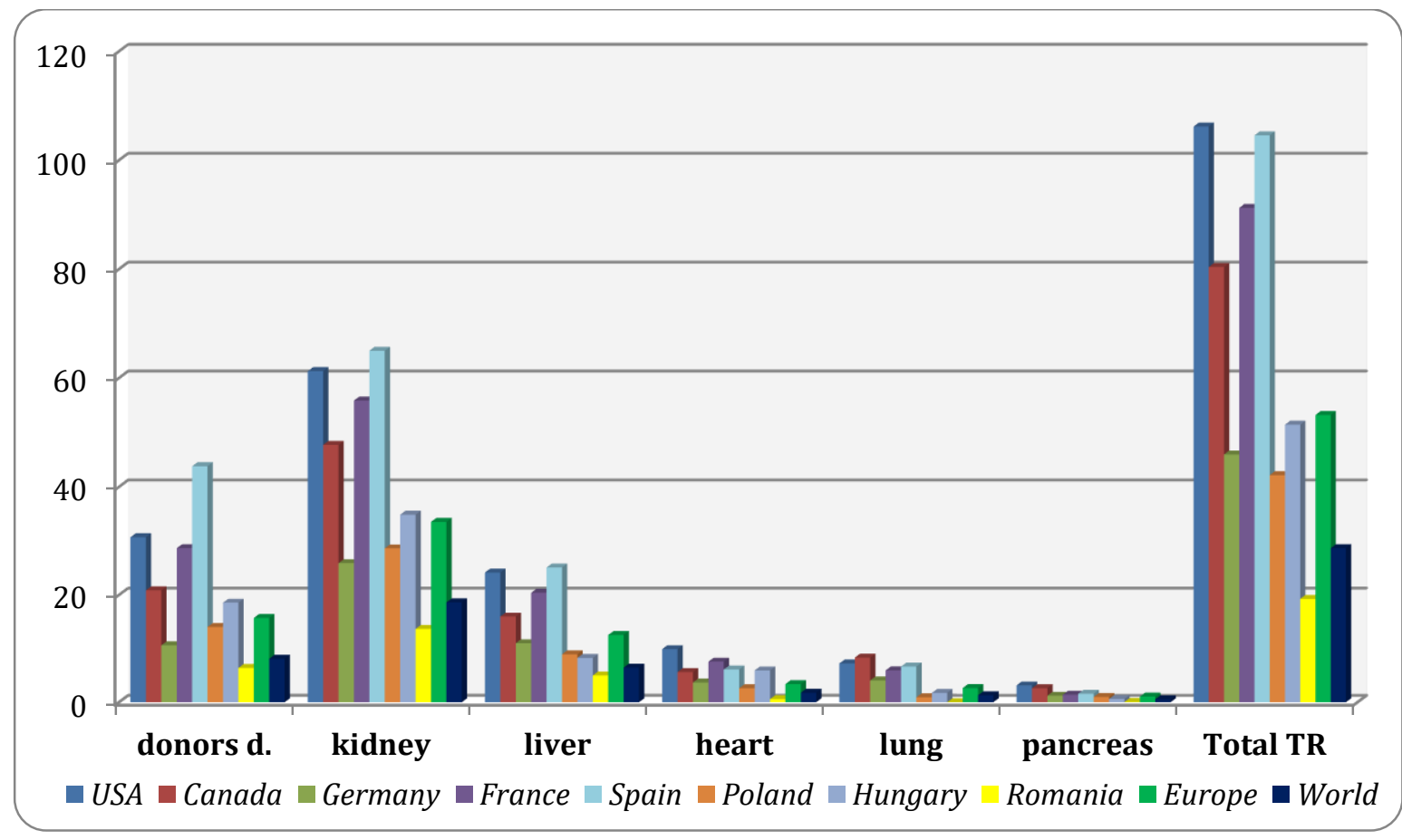

DOI: 10.2478/picbe-2019-0037, pp. 421-434, ISSN 2558-9652| Proceedings of the $13^{\text {th }}$ International Conference on Business Excellence 2019 
Figure 1. Transplantations per types and donor rates per million inhabitants in selected countries and regions, 2016

Source of data: http://www.transplant-observatory.org/summary/

\section{Developing transplantation at St. Maria Clinical Hospital, Bucharest}

St. Maria Clinical Hospital, a public hospital of 300-beds, is the second center of liver transplantation in Romania since 2014 (after "Fundeni" Institute), and the first center of lung transplant since 2018. Persuasive endeavor was necessary to convince authorities and people to develop lung transplantation here instead of sending the cases abroad, at higher efforts and costs (e.g. for successful lung transplant, total cost in our hospital is up to 90,000 Euro, versus 120,000 Euro paid abroad for procedure only, while for liver transplant is up to 50,000 Euro vs. 80,000-90,000 Euro abroad). Opposers tried to induce the idea that the Pneumophtisiology Institute "Marius Nasta" from Bucharest would be the best choice for lung transplantation, which would sound logical if we ignore the poor conditions and lack of equipment from their 100-years-old buildings, confirmed by recent deceases of patients due to nosocomial infections, followed by complaints of their doctors.

Basis of this Transplantation Center was built several years ago by transforming a common general surgery ward into a Hepato-pancreato-biliary surgery (HPB) center completely modernized and well-equipped, with an excellent team, after a consistent and continuing training in Hannover - Germany. Our purpose was and is to increase the life expectancy and quality of life of our patients with HPB pathology at reasonable costs, after analyzing the incidence, distribution and features of HPB cases in Romania. Several other services (medical tests and investigations, blood transfusions, gastroenterology, pneumology, thoracic surgery, pathology) were considerably developed or newly introduced in order to respond to our Center needs. On the other hand, the close collaboration between Romanian team of surgeons, including experts from other hospitals, and the German team from Hannover, continued after the training programme with successful transplantations performed together in our new Center. (Copca et al, 2013) (Copca et al, 2018)

All the achievements were possible after coordinating a significant rehabilitation and endowment with modern medical equipment, supported by the local authorities. Then, we were able to build up, motivate, train and retain a great medical team, despite the severe migration phenomenon specific for our country; over $21 \%$ of our personnel are now physicians and $45 \%$ are nurses, meaning over $66 \%$ of total staff is medical. In these conditions, we offer high quality services in: general surgery, liver surgery, plastic and reconstructive surgery, thoracic surgery, oral \& maxillofacial surgery, otorhinolaryngology (ENT), gastroenterology, intensive care, internal medicine, pneumology, medical rehabilitation, oncology, cardiology, rheumatology, neurology, lab medical tests and complex imagistic. Our most complex and sophisticated services are: major and minor liver and pancreatic resections (>200), successful liver transplant (42), lung transplant (4 in 6 months), breast cancer removal and breast reconstruction $(>600)$, oncological procedures $(>100)$, gastrectomies, esophagectomies, esogastric procedures, thoracic minimal invasive procedures, ultrasound-guided pericardiocentesis by Seldinger technique, complex procedures on digestive system (>200) and sophisticated ENT interventions.

Our cases are clinically classified as following: 35\% musculoskeletal system, 20\% digestive system, 14\% ENT, 8.7\% liver-pancreas, 5.1\% breast and skin, 2,7\% reproductive 
system, $2.5 \%$ circulatory system, $2.2 \%$ kidney and urinary tract, $1.9 \%$ nervous system, $1.3 \%$ respiratory system, $0.7 \%$ endocrine, nutrition/metabolic, $0.7 \%$ cancer.

For a more precise overview of the organization, values achieved during latest five years at the main performance indicators are presented in the table below.

Table 3. Main performance indicators of the hospital, during 2013-2017

\begin{tabular}{|l|l|l|l|l|l|}
\hline Indicators & $\mathbf{2 0 1 3}$ & $\mathbf{2 0 1 4}$ & $\mathbf{2 0 1 5}$ & $\mathbf{2 0 1 6}$ & $\mathbf{2 0 1 7}$ \\
\hline Number of outpatient visits & 26,316 & 23,519 & 25,292 & 23,316 & 22,656 \\
\hline Number of day-hospitalizations & 4321 & 4070 & 4833 & 4105 & 11885 \\
\hline Number of inpatient cases (discharges) & 11,921 & 11,740 & 12,173 & 11,746 & 10,857 \\
\hline Number of hospitalization days & 57,822 & 58,583 & 65,247 & 64,251 & 56,457 \\
\hline Average length of stay - days (ALOS) & 4.84 & 4.99 & 5.36 & 5.47 & 5.20 \\
\hline Case-mix index (CMI) & 1.0708 & 1.1505 & 1.1511 & 1.5196 & 1.5800 \\
\hline \% emergencies of total inpatient cases & $34.70 \%$ & $35.30 \%$ & $27.82 \%$ & $23.53 \%$ & $23.58 \%$ \\
\hline Hospital mortality rate & $0.37 \%$ & $0.60 \%$ & $0.79 \%$ & $0.99 \%$ & 0.82 \\
\hline Hospital-acquired infection rate \% & 0.18 & 0.17 & 0.07 & 0.3 & 0.72 \\
\hline $\begin{array}{l}\text { Concordance between discharge and } \\
\text { admittance diagnostics }\end{array}$ & $57.1 \%$ & $54.40 \%$ & $50.00 \%$ & $53.04 \%$ & 53.73 \\
\hline Weighted-case tariff (Romanian lei) & 1442 & 1442 & 1783 & 1783 & 1783 \\
\hline
\end{tabular}

Source: St. Maria Clinical Hospital statistical reports, 2013-2017

Values registered at main performance indicators mark a good evolution during last years, compared with national averages, especially in terms of constant increasing range, complexity and severity of cases treated, at low length of stay (effectiveness and efficiency) - except for transplants and very severe cases, declaring all the hospital-acquired infections and controlling/ containing them, developing day-hospitalization. In addition, satisfaction of our patients with services and care received in hospital is high, and degree of professional fulfillment of medical staff is also very high, as our periodical studies show.

We strive to measurable improve the health state of our patients through high quality services adapted to each patient needs, practicing evidence-based medicine with the best specialists and equipment, continuous training and development, in a proper environment. Our values are: accessibility, "patient comes first", high professionalism, clinical safety, collaboration, respect, sustainability, efficiency. 
Table 4. SWOT Analysis of the St. Maria Clinical Hospital

Analysis of internal environment

Strengths

Hospital category $2^{\text {nd }}$ without conforming plan

Completely rehabilitated, modernized building

Excellent medical equipment and instruments

Very good nonmedical services (accommodation, catering, cleaning)

- $\quad$ All hospital wards are clinical, providing high specialized services, national accession of patients

- $\quad$ Very good medical staffing, well trained, reputed physicians, with great medical achievements Accredited Center for liver, pancreas and lung transplant, all interventions successful

Wide range of medical tests and investigations

- Performing training and research activity, projects, studies; accessing national and European funds Frequent organizing courses, conferences, scientific events in the hospital

Patient satisfaction with quality of services and care received in hospital is high

- Continuous hospital development
Weaknesses

- Under-used capacitate on certain hospital wards / services

- Decrease in outpatient activity

- High level of hospital costs due to medical technology, complexity \& severity of cases treated, high expertise of personnel, training and research activities performed Laborious, difficult reporting for postaccreditation monitoring

- $\quad$ Update necessary to several procedures and clinical protocols

- Week presentation and publicity of our services, team, achievements, performance Insufficient administrative space Hospital website is not up-to-date Acute deficit of parking lots in hospital yard and outside, given the central location.

Analysis of external environment

Opportunities

Considerable support from City Hall

- $\quad$ Significant rising of salaries of medical staff working in public hospitals since 2018

- Accessing national health programs

- Collaborations with reference medical\& research European centers (ex. Hanover)

- Accessing national and European funds for specific hospital R\&D projects

- Excellent collaboration with public authorities Bucharest Hospital and Medical Services Administration, Health Insurance Fund, Public Health Authority, Ministry of Health, Sect.1 City Hall, National Transplant Agency, National Authority for Health Quality Management

- Opportunities for public and private collaboration, Bucharest is the biggest medical center in Romania

- Development actions envisaged in National Health Strategy 2014-2020, including new hospitals.

\section{Threats}

- Frequent political and legislative changes

- Demotivation of administrative staff after rising salaries for medical staff only Some hospital accreditation indicators and standards are very difficult to accomplish Reimbursement mechanism for hospitals does not encourage efficiency, nor competition

- $\quad$ Significant migration of doctors \& nurses Poverty negatively influencing patient health and behavior, delay in hospitalization

- $\quad$ Continuous negative campaign against public hospitals and doctors affected their image and orient patients to private sector Media scandals decreased organ donation and consequently transplants even more, despite increasing needs of patients.

Source: authors own work

Next step is to build a modern Multi-organ Transplantation Center of national and regional importance, within this hospital, following consecrated European models. Premises: official approvals and support from city hall and health authorities; transfer of land property from Bucharest to sector city hall; pre-feasibility study and draft project of the new building; excellent medical equipment available in the hospital; excellent medical team trained abroad including in Hannover multi-organ center, with notable achievements; consistent experience acquired in complex surgery and transplantation; many research projects, studies and scientific events attained by our clinical personnel; continuous hospital development during the past 15 years. 
Business advantages for our public hospital:

- we convinced local authorities (both municipal and sectorial city halls) to support our hospital with significant funds for modernization and medical equipment;

- excellent working conditions determined very good doctors to work in our hospital, provide new services or techniques and bring their patients (,patient follows the doctor" principle), in spite of competition with private and public hospitals in the country and abroad;

- benefit from considerable salary rising in public health sector (25\% in 2016, and up to $100 \%$ only for medical personnel in 2018); in addition, our medical staff working on transplantation benefit from another $70 \%$ increment of their monthly salary, which is a strong financial motivation for doctors and nurses, and also a disincentive for under-the-table payments (bribes) received from patients;

- our catering, cleaning, washing and security services are efficiently externalized, thus decreasing our nonmedical expenditures and increasing spaces for medical activity;

- as nonprofit public organization, our hospital uses the financial surplus registered every year, for development and quality of services (no tax, no dividends);

- according to the law, public hospitals do not account depreciation for capital assets, hereby there is no pressure for investment recovery;

- despite the critical situation of (public) hospital-acquired infections in Romania, our facility is recognized for its very low rate of infections, honestly reported;

- due to our internal efficiency, up to $60 \%$ of the amount received for transplantation is saved, depending on each case (besides 30,000-40,000 Euro saved by the state per each transplant achieved in Romania versus abroad);

- besides successful transplantation, our surgical teams also perform new or sophisticated procedures / interventions, and approach very complex or severe cases effectively avoiding or prevailing complications, on an increasing pathology range; the Minister of Health granted our Surgery and Transplantation Center with the Health Excellence Award in 2015;

- our medical teams access additional funds in the hospital for clinical research and continuous education, representing another incentive;

- our financial management is conducted in full respect for generally accepted accounting principles (GAAP), Romanian legislative framework, accountability and efficiency, despite so many frauds and arrears registered in the public system.

The Center is projected as a new modern building $3 \mathrm{~S}+\mathrm{P}+7$ (seven over-ground floors plus three underground floors) in the hospital yard, linked with the existing building, totaling $7,000-8,000 \mathrm{~m}^{2}$ at a maximum cost of 2,500 Euro/ $\mathrm{m}^{2}$ (totalizing up to 17-18 millions). The organizational structure of the center will comprise: medical laboratories for complete testing and medical imagistic; medical wards of cardiology, oncology, pneumology, neurology, nephrology; surgical wards of thoracic surgery, cardiac and vascular surgery, interventional cardiology, urology; extended transplantation clinic; operation theater; intensive care and anesthesiology ward; patient rooms including with high accommodation amenities (comfort); ambulatory; training and conference center; technical and administrative rooms; underground parking place. Hospital number of beds will remain the 
same (300) by redistribution of the current beds according to the new structure after public health authorization.

Financing sources for the center were identified as the Bucharest Municipal City Hall and Sector 1 City Hall in partnership, while the hospital will participate with the medical equipment already available and the almost all the medical personnel as necessary.

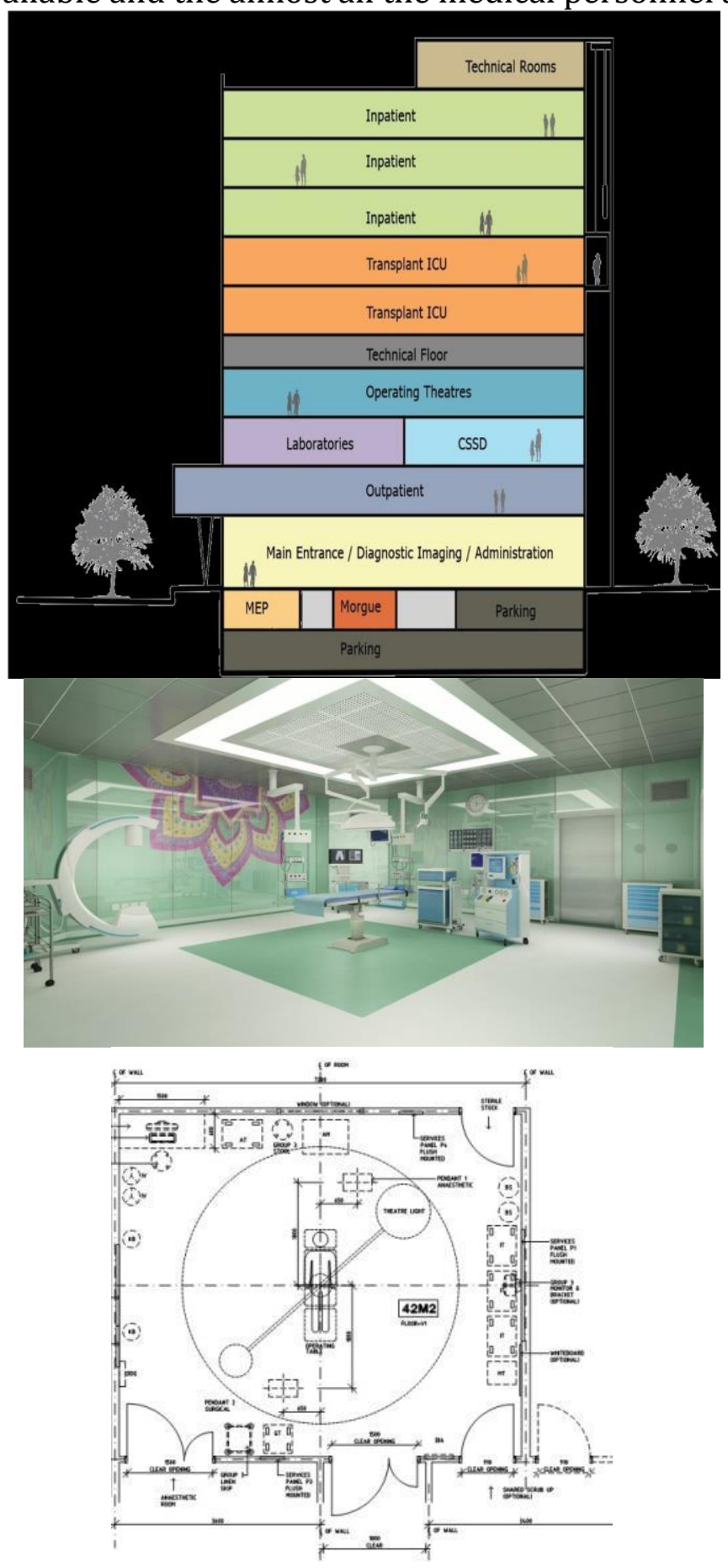

PICBE | 432 


\section{Conclusion}

Romanian citizens in need for these life-saving medical services as transplantation have the human right to receive them, at the highest quality as possible, provided in the closest accredited centers available, at reasonable costs covered by the state (of 30,000-40,000 Euro savings per transplantation than abroad), instead of migrating abroad to confront discomfort and catastrophic payments for the entire episode (consisting in medical tests, transplant, post-surgical care, transportation, post-hospitalization surveillance). Currently, transplantation activity in our country is at a minimum in comparison with people needs and capacity of the medical system, even compared to precedent years, with only 3.3 deceased donors / million inhabitants (compared to European average of 18.74), and consequently just 10.91 transplants / million inhabitants (compared to European average of 61.64) in 2017.

Romanian potential for overspecialized surgery are greater than actual practice. Experience indicates that multi-organ transplantation centers are more effective and efficient than separated ones, by concentrating the best specialists, technology, knowledge and resources available for harvest, preservation, transplant and care, thus improving the health outcomes (donors, successful transplants, lives saved, quality of life), prestige, retention of excellent professionals and trust in our healthcare system, at lower costs than in developed countries. Moreover, this Center will also confer the best conditions for medical research and, in near future, the great opportunity to become a local hub for training specialists in this field, thus strengthening the Romanian and Eastern-European capacity of human organ transplantation.

Given our achievements, premises and advantages, and the patient needs for transplantation, briefly presented in this paper, we propose the development of the first Multi-organ Transplantation Center in Romania and in the Eastern-European Region, within the St. Maria Clinical Hospital, in order to better respond to the specific needs of patients waiting for a transplantation to save their lives and improve the quality of life. This initiative needs a substantial organizational and financial effort, but the Center is necessary, sustainable, effective and efficient on long term, despite all the adversities faced by the transplantology in our country. Concomitant, unceasing information-educationcommunication campaigns for organ donation have to be done at national and local level, otherwise transplantation cannot be sustained. Expected results include the revitalization of organ donation from population, and implicitly the transplantation, at the highest level ever registered nationally, followed by an increase of $15-20 \%$. On the other hand, at the great event of 100 years of Unified Romania, the effort of retaining good physicians and great leaders in their own country and facilitating their medical performances here, instead of migrating abroad, it would be a managerial and governance duty to consider.

\section{References}

Barker, C. F., \& Markmann, J. F. (2013). Historical overview of transplantation. Cold Spring Harbor perspectives in medicine, 3(4), a014977. doi:10.1101/cshperspect.a014977

Bjornberg, A. (2018). Euro Health Consumer Index 2017 Report, Health Consumer Powerhouse, 2018-01-29 (pp. 19, 25-26)

Copca, N., Chirita, D., Stroescu. C., Hrehoret, D., Popa, L. (2018). HPB Surgery and Transplantation Center of Clinical Hospital St. Maria, Bucharest: constitution, 
experience, future, HPB Surgery and Liver Transplant National Congress, Cluj-Napoca, Sept. 20-22, 2018

Copca, N., Hanna, A., Pivniceru, C., Campeanu, I. (2013). Experimental Liver Transplantation on Pigs - Technical Considerations, Chirurgia, 108(4):542-6 Aug.2013Duran, A., Chanturidze, T., Gheorghe, A., Moreno, A. (2018). Assessment of Public Hospital Governance in Romania: Lessons from 10 Case Studies, International Journal of Health Policy and Management, pp.1-12, retrieved from https://www.ijhpm.com/article_3581.html

Dye, C. F. \& Garman, A.N. (2006). Exceptional Leadership. 16 Critical Competencies for Healthcare Executives, Health Administration Press, Chicago, IL

European Parliament and European Council. (2010). Directive 2010/45/EU on standards of quality and safety of human organs intended for transplantation, Official Journal of the European Union, 7 July 2010, retrieved from https://eur-lex.europa.eu/legalcontent/EN/TXT/?uri=celex:32010L0053Global Observatory on Donation and Transplantation, the World Health Organization. (2009). Global Glossary of Terms and Definitions on Donation and Transplantation, Geneva, November 2009, retrieved from https://www.who.int/transplantation/activities/GlobalGlossaryonDonationTranspl antation.pdf?ua=

Global Observatory on Donation and Transplantation (GODT), Summary transplant data per country, region and global, 2016-2017, retrieved from http://www.transplantobservatory.org/summary/

Hodgetts, S. (2011). Effective Leadership: The Key To Successful Hospital Management, Health Management, Volume 13, Issue 5/2011, retrieved from https://healthmanagement.org/c/hospital/issuearticle/effective-leadership-thekey-to-successful-hospital-management

Organ Procurement and Transplantation Network (OPTN), U.S. Department of Health and Human Services, the Transplantation, 2018, retrieved from https://optn.transplant.hrsa.gov

Saltman, R.B., Duran, A., Dubois, H.F.W. (2011). Governing Public Hospitals. Reform strategies and the movement towards institutional autonomy. European Observatory on Health Systems and Policies, WHO Regional Office for Europe (pp.18-22)

St. Maria Clinical Hospital, Statistical, Clinical, Financial reports; Managerial and Strategic Projects, 2013-2017

West, M., Armit, K., Loeventhal, L., Eckert, R., West, T., Lee, A. (2015). Leadership and Leadership Development in Health Care: The Evidence Base. Faculty of Medical Leadership and Management, Center for Creative Leadership, The Kings Fund, UK, (211), $\quad$ retrieved from https://www.kingsfund.org.uk/sites/default/files/field/field_publication_file/leade rship-leadership-development-health-care-feb-2015.pdf 